\section{Quashed convictions reignite row over British cot deaths}

Laura Nelson, London

The British government is set to review the cases of 258 British parents convicted of murdering their own babies in the past decade, after the Court of Appeal threw out the expert testimony used in three such convictions.

A row has erupted over testimony given by retired paediatrician Roy Meadow. In 1977, Meadow, then at St James's University Hospital in Leeds, proposed the condition 'Munchausen syndrome by proxy' (R. Meadow Lancet ii, 343-345; 1977), which describes parents who deliberately harm their children to draw attention to themselves. In many court cases he testified on the probability that this syndrome was responsible for sudden infant death syndrome, or SIDS.

Meadow has been pilloried in the British press for his role as expert witness in the three convictions, and is under investigation by the General Medical Council, which governs British medicine. He is due to appear before its professional conduct committee this summer.

Lawyers representing Meadow have advised him not to comment on the charges, he says. But some scientists have privately sprung to his defence. One senior paediatrician contacted by Nature said that Meadow "has made important contributions" to the understanding of cot deaths and had conducted himself with "skill and compassion".

Others feel that Meadow has allowed his judgement to be clouded. "Meadow has gone over the top," says Robert Carpenter, who researches SIDS at the London School of Hygiene and Tropical Medicine. "He sees child abuse behind every tree."

Joyce Epstein, director of the Londonbased charity, the Foundation for the Study of Infant Deaths, called for more thorough investigation into each death. "There should also be an examination of 40 different tissues, including the whole brain," says Carpenter.

Peter Fleming, a child-health expert at the University of Bristol, will publish an article next month in the British Medical Journal calling for such detailed investigations to be performed within 24 hours of the baby's death. But doctors are reluctant to enter the ethical and legal minefield of such investigations, making a uniform regime tough to implement.

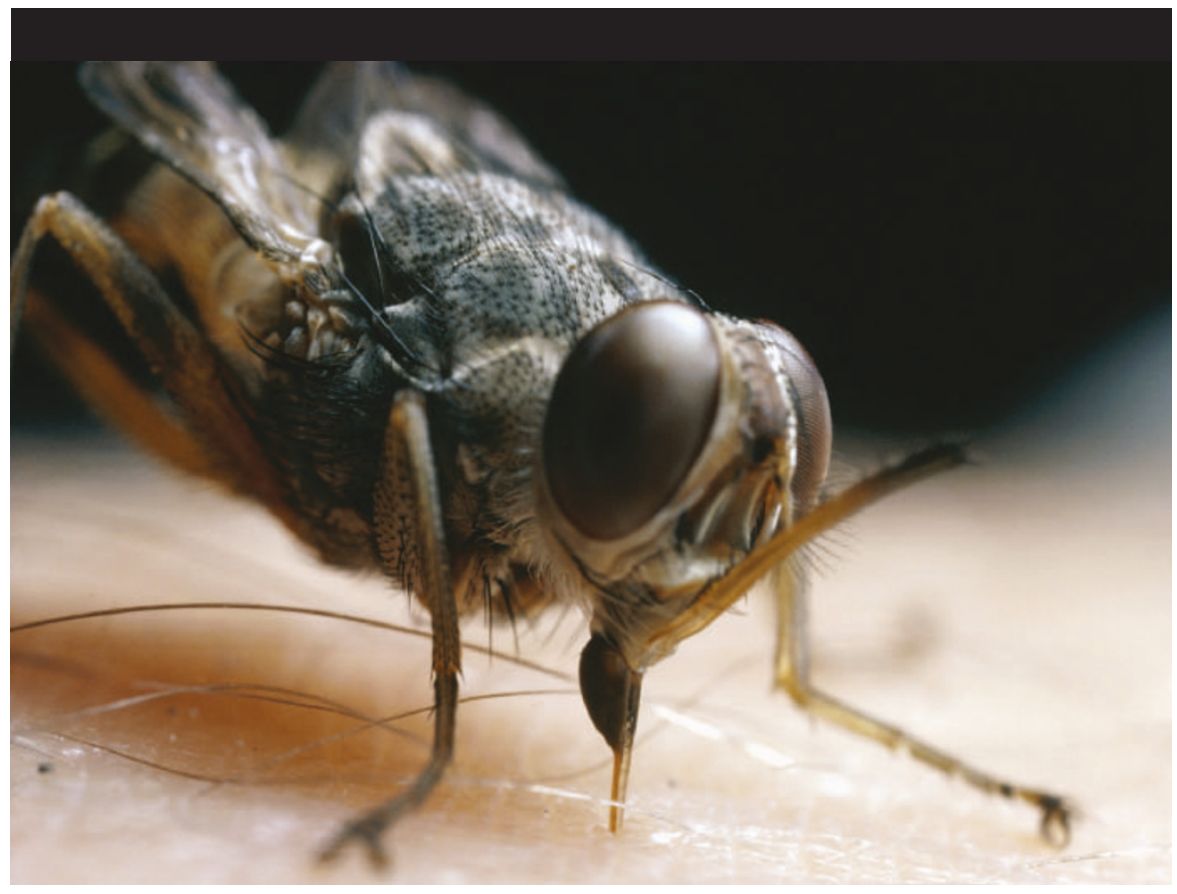

Death dealer: the tsetse-fly Glossina morsitans transmits African sleeping sickness.

\title{
African labs win major role in tsetse-fly genome project
}

\section{Declan Butler}

An international research consortium has been formed to sequence the genome of the tsetse-fly, the pest that carries disease to millions of people and cattle in Africa.

The tsetse-flies, species of Glossina, carry trypanosome parasites that cause human sleeping sickness (African trypanosomiasis) and animal trypanosomiasis, a scourge of African cattle that is estimated to cost farmers US $\$ 4.5$ billion a year.

The International Glossina Genomics Initiative, which was launched at a meeting in Geneva on 19-20 January, plans to break new ground by involving African scientists from the start. If the initiative is funded, most of the high-throughput sequencing will be done in Europe and the United States, but the databases will be housed at the South African National Bioinformatics Institute (SANBI) at the University of Western Cape, near Cape Town. Much of the genomic and bioinformatics analysis will be carried out in Africa.

African trypanosomiasis infects up to half a million people, and is fatal if untreated. The main therapy available, a 50-year-old drug called melarsoprol, kills up to $10 \%$ of those who take it. With no new drugs in view for at least a decade (see Nature 424, 10-11; 2003), a sequenced genome could help researchers better understand the interaction of the pathogen with its fly and human hosts and its transmission to humans, says Serap Aksoy, head of Yale School of Public Health's Division of Epidemiology of Microbial Diseases, who attended the meeting. "This is a developing-country problem; it's very important that developing countries be involved from the beginning," she adds.

Winston Hide, director of SANBI, says that the inclusion of African nations recognizes their efforts to create a workforce skilled in genomics. The South African government has pledged $\$ 40$ million over ten years to create a national bioinformatics network. Over the past four years, the World Health Organization has also funded bioinformatics training courses in Africa, Latin America and Asia. "We have trained a cadre of scientists who are from very poor places, but highly qualified," says Hide.

The consortium was formed at a meeting held under the auspices of the United Nation's Tropical Disease Research programme. It brings together scientists from more than a dozen sleeping-sickness labs and genome centres, many of which are already sequencing the Trypanosomabruceigenome.

The first goal will be to check whether the choice of fly to be sequenced - Glossina morsitans - is a valid model for the more important vector of human disease, G. palpalis. The latter's genome is full of repeat sequences and weighs in at some 7,000 million bases $(\mathrm{Mb})$, or twice the size of the human genome. That of G. morsitans, at 600 $\mathrm{Mb}$, is more manageable.

The costs of this first nine-month phase, which would involve small amounts of sequencing, can be covered by coordinating existing funds among the consortium partners, says Aksoy. The consortium would then seek \$10 million to sequence and annotate the complete genome by 2006 . 